\title{
Research on Translation of Xi'an Red Tourism Public Materials under the Perspective of Ecological Translation
}

\author{
Zheng Zhao ${ }^{1}$ \\ ${ }^{1}$ Xi'an Fanyi University, Xi'an, Shaanxi, 710105
}

KEYWORDS: Ecological Translation; Red Tourism Materials; Multidimensional Conversion; Translation Studies

\begin{abstract}
Hu proposed ecological Gengshen translation studies believe that the quality of the translation depends on the extent of conversion of multi-dimensional, that is, respect for the translation of ecological environment at the same time, pay attention to the translator of adaptation and selection. China's red tourism materials language translation conversion factors, cultural factors involved, so that the ecological conversion of translation studies relating to the three-dimensional system that can provide a more comprehensive perspective to red tourism materials Translation Studies. From Eco translation studies, combined with the author about the practice of translation $\mathrm{Xi}$ 'an red tourism materials, and discusses the relevant translation strategies.
\end{abstract}

\section{Introduction}

Shaanxi has rich tourism resources, not only has Chinese roots, world-class landscape, the Silk Road economic belt, more importantly, Shaanxi, as the cradle of Chinese revolution, with many red tourism resources, is to achieve "China Dream" spiritual home . Xi'an, capital of Shaanxi as is the spread of revolutionary culture is an important place, has attracted many domestic and foreign tourists. In order to let more foreign tourists to understand the spirit of the red, increase the influence of the red tourist attractions, the priority is to enhance the translation of tourism materials Xi'an red readability, increase the translation efforts. The author from the perspective of translation studies ecological point of view, Xi'an red tourism materials, for example, combining the characteristics of red tourism materials, through the author's translation practice, discusses the relevant translation strategies.

\section{Second, the theory of ecological Translation}

Translation ecological theory by domestic scholars Gengshen Hu suggested that it is from the original inherent ecological structure of the proposed translated works are selected and followed in the process of translation of the original ecological structure inherent to reproduce in another language. Ecological Translation Studies believes that translation is "to adapt to the ecological environment translator selection activities." This view with particular emphasis on two aspects, namely the translation environment and translator adaptation and selection. Translation ecological environment not only refers to the language environment, and covers a variety of original world and the world cultural translator, communication, and social face. Ecological translation studies from a broader perspective of translation, rather than limited to the perspectives of language level. Adaptation and selecting a translator from this concept, we can see more emphasis on ecological 
translation studies translators as the center, so from the point of view of ecological translation, the translation process should be adapted to a translator and the translator of choice alternating cycle process [3].

Translation ecological theory has a strong operational and practical significance in practical applications. Red tourism materials have a significant translation "Translation ecological environment": Before translation, the translator should also be considered in its original language and the target language in the world, proficiency in the source language and the target language, in-depth understanding of the cultural and social background of the two languages, properly handle the relationship between translation initiator and target readers and is met by the initiator translation requirements, the translation of the translation reader feedback have foreseen, and through the personal practice of understanding to be translated into English propaganda materials and occasions specific circumstances; the translation, the translator of the above "Translations ecological environment", respectively, from the "3D" (language dimension, cultural dimension and communicative dimension) etc. repeated the translation selection and elimination carefully until you have a table defined with the original most "integration of adaptation options" propaganda highest data translation fit the target language fluent in line with the target language fluently, and can skillfully and properly handle cultural differences, successfully convey communicative intentions; in the final stages of translation, according to Economic Literature translation the principle of "survival of the fittest" to be examined, retain and promote good translation; translation by bad translation or retranslation [5]. In summary, the data translation propaganda throughout the process, in terms of translation methods, principles and criteria, can be translated Ecological Studies reasonable explanation. Visible, exist between ecological Translation Studies and Economic Literature Translation ties, ecological Translation Studies as a new theoretical model of Economic Literature Translation must be a guiding role.

\section{The Characteristics of Red Tourism Materials in Xi'an}

2004-2010 National Red Tourism Development Plan of the Red Tour defined. Red tourism refers to the great achievements of the Chinese Communist Party led the people to build memorial formed in the revolutionary struggle and stop times, markers for the carrier to carry their revolutionary history, revolutionary spirit and revolutionary deeds for the content, organization and reception of tourists to carry the memory of learning, sightseeing tours subjectivity.

The author collected by various red tourism attractions in Xi'an Economic Literature, and its analysis, found that red Xi'an tourism materials has the following language features.

First, Xi'an red tourism materials described in the more revolutionary historical events, such as " seventy-seven' Incident", "Xi'an Incident", "Northern Expedition" and so on. Secondly, Xi'an red tourism propaganda materials contain a large number of political, military elements, such as the "Red Army focal points", "National Revolutionary Army", "KMT-CPC cooperation, solidarity against Japan", "anti-Japanese national united front." Again, there is a red Xi'an tourism materials in some of the poems, couplets, not only carry forward the revolutionary spirit also showed a variety of Chinese specialties.

Thus, different from the ordinary red tourism tourist translate translation, narrative has a strong political component more and culture-rich features help deliver Chinese revolutionary history and Chinese culture. However, due to differences between Chinese and Western cultures and languages, how to make the translation by Western tourists a comprehensive understanding of the history of Chinese revolution and understand the spirit of the red is a serious problem in this topic. 


\section{Xi'an Red Tourism Materials Translation under the Perspective of Ecological Science}

Translation Studies advocate ecological dimension from the language, culture and communication dimensional three-dimensional perspective of the start, Xi'an red tourism materials for analysis and translation practice, so that the translator extent multidimensional transformation.

The so-called "language-dimensional adaptive choose Convert", that is the translator of the language in the form of adaptation options to convert. Red tourism materials translations semantic and linguistic analysis from the perspective of two expressions. To ensure that the target language can fully convey the source language content, combined with the special historical background of the appropriate choice of the target language expression.

Example: Only park area, there is a historical background information: December 18, 1936, Zhou Enlai, Communist representatives on behalf of the CPC resident Yang Wenbin Department who came to "stop Park", with Yang Hucheng to discuss matters relating to the peaceful settlement of the Xi'an Incident.

This information about the translations have two questions: 1. "Only park" means. 2. The way the language of the translation information. About "Only park" translation, I believe that not only the use of transliteration, translation studies should ecological point of semantics to explain, to ensure that the translation reader "Only park" a more comprehensive understanding. About the global structure of the language, the subject of the sentence is "Zhou Enlai on behalf of the CPC," two verb "come", "discussing", but the emphasis is on the message of the "discussions", this is to "stop Park" purposes. In order to reflect the English translation of primary and secondary information from the perspective of ecology linguistic expression departure, I propose translated: On December 18th, 1936. Accompanied by Zhang Wenbin, the resident in Yangbu county, Communist representative Zhou Enlai discussed peaceful settlement of the Xi'an Incident with Yang Hucheng in Zhi Yuan ("stop" is from "Ge only as Wu" which means military forces are to be used only for the maintenance of peace and order.)

Introducing Xi'an Revolution Park, there is a message: Liu Zhenhua the siege in August-old, set fire to 10 acres of wheat fields outside the city, forced labor around the city digging a ditch three kilometers cut off, an attempt to force the city army surrender.

This sentence logic clearer, the first sentence is the time adverbial, the second sentence is the focus of the whole sentence, The last sentence refers to the object. In addition, "Liu Zhenhua" warlords of the Northern Warlords period, in order to allow a comprehensive understanding of the original target readers, the author suggested adding "the warlord" supplementary explanation.

Recommendation translated: During 8 months of besieging the city, the warlord called Liu Zhenhua, (revolutionary color) set fire to 100,000 acres of wheat files outside the city, forced the civilian to dig a ditch stretching about 3 kilometers in order to compel soldiers and militaries to surrender.

"Cultural dimension of conversion options for adaptation", which concerns transfer and interpretation of bilingual translator cultural connotation in the translation process. This cultural dimension of adaptation options to convert that attention to cultural differences between the source language and target language culture in the presence of the nature and content "from the target language to avoid misinterpretation original cultural perspectives, language translator converts the source language during the same time, concern adapt the whole cultural system of the language belongs. "[2]. Xi'an red tourism materials involves many Revolution historical and cultural background, translators need to be passed to the reader.

For example: For the "Xi'an Incident" translation, I suggest: transliteration plus annotation methods. 
Translation: the Xi'an Incident (which happened in Xi'an on December 12, 1936, when Zhang Xueliang and Yang Hucheng, the Kuomintang generals influenced by the Chinese Communist Party's policy of an anti-Japanese national united front, imprisoned Chiang Kai- shek, the leader of Kuomintang, and requested that he stop the civil war and unite with the Communist Party to be against the Japanese invaders).

Another example: the Eighth Route Army in Xi'an office memorial sentence: Mr. Boren Xi'an celebrities to borrow Jin "Bamboo Forest" beauty biography, the book title sages, inlaid in the village the first gate.

Bo Ren, the well-known in Xi'an, inscribed "Village of Seven Sages" (which is on the basis of the reputation of seven talent hermits in the Wei and Jin dynasties (AD 220-420) on the front arch of the village

Bamboo Grove refers to the Three Kingdoms period Wei Zheng Shi years (240-249), Ji Kang, Shan Tao, Xiang Xiu, Liu Ling, Ruan Xian Rong and seven people, prior Seven Sages said. Because often the time of Hill County under bamboo, drinking, singing and wanton Hearty, Seven Sages of the world that, after the place name bamboo collectively. The word has a history and culture, how to make Westerners understand it? I believe that the literal and comments combination of approaches can help Westerners understand, while helping to promote the Chinese culture and history.

"Communicative dimension of conversion options for adaptation" that translator Bilingual communicative intention concern adaptation options and their translation process. This communicative dimension adaptability select conversion requirements translator "In addition to the transfer of language and culture to convert the information to select the conversion focus on the level of communication, concern whether the original intent of the communication to be in the translation reflect "[2]. When a similar target readers to read the translation and the effect produced by the original readers read the description generation effect, the two languages will be implemented broadly consistent with communicative intention.

For example: the famous patriotic general Yang Hucheng Mausoleum was built in the $1 \mathrm{~km}$ Town Wei Qu Chang'an District office, back on the original Fengqi, North and Dugong Ci adjacent to a beautiful environment, beautiful scenery.

The sentence introduces the location and pleasant surroundings of General Yang Hucheng Mausoleum. Related to "Changan Qu Wei Qu Town", "Fengqi original", "Dugong Ci" has the characteristics of Xi'an local geographical and cultural terms, if the literal to Western readers, will inevitably result in the burden of understanding, cannot arouse interest Westerners scenic tour, the author suggested translation province. Test translation the cemetery of Yang Hucheng, the famous patriotic general has friendly environment with enchanting beauty. Visible, I just translated the beauty of the calling function to achieve the text tourism to attract Western tourists to achieve a communicative intention.

\section{Conclusion}

Translation as red tourism propaganda texts, whose main purpose is to attract Western tourists to visit and feel red culture, carry forward the spirit of the red, so how to choose the translation strategy, accurate and comprehensive transmission of information is very important. Translation ecological science, ecology as a way of translation studies, translation red tourism materials provides a new perspective.

Xi'an Red Tourism as one of the rich tourism resources, attracting domestic and foreign tourists. Translation about Xi'an red tourism propaganda materials for the correct and appropriate to convey 
meaning, communication plays a vital role in red culture. Translation Studies from the ecological point of view, a language-dimensional MR cultural dimension and communicative dimension conversion convey the original meaning both comprehensive and accurate, but also more effective dissemination of Chinese culture red, and can provide some inspiration for the English translation of other texts.

\section{Acknowledgements}

Proj: Xi'an Social Science Fund, One of the Products of on Translation of Publicity Materials of Red Tourism in Xi'an

Project No. 15XF18.

\section{REFERENCE:}

[1] Hu Gengshen. Translation as Adaptation and Selection [M]. Wuhan: Hubei Education Press, 2004: 128.

[2] Hu Gengshen. focus of research and Theory [J]. ecological Translation Studies Chinese translation, 2011 (2): 5-9.

[3] Su Huijuan. Ecological Perspective Translation of Public Signs Translation from- to Shanghai World Expo will be the main slogan as an example [J]. Shanghai Translation, 2010 (2): 39-42.

[4] Sun Yifeng. Angle of culture-Cultural Translation and Translation Theory [M]. Beijing: Tsinghua University Press, 2004: 128.

[5] Zhao Zheng. Chinese Translation of Public Signs Ecological Studies Ways to Xi'an Translation -Translation of Public Signs example [J]. Ningbo Radio \& TV University, 2014, 12 (2): 52-53. 